\title{
ERRATUM
}

DOI: $10.1007 / \mathrm{s} 00376-016-0001-4$

\section{Erratum to: Comparison of a Very-fine-resolution GCM with RCM Dynamical Downscaling in Simulating Climate in China}

\author{
Donglin GUO $^{* 1}$ and HuijunWANG ${ }^{1,2,3}$
}

${ }^{1}$ Nansen-Zhu International Research Center, Institute of Atmospheric Physics, Chinese Academy of Sciences, Beijing 100029

${ }^{2}$ Climate Change Research Center, Chinese Academy of Sciences, Beijing 100029

${ }^{3}$ Collaborative Innovation Center on Forecast and Evaluation of Meteorological Disasters,

Nanjing University of Information Science \& Technology, Nanjing 210044

Erratum to: Guo, D. L., and H. J. Wang, 2016: Comparison of a very-fine-resolution GCM with RCM dynamical downscaling in simulating climate in China. Adv. Atmos. Sci., 33(5), 559-570, doi: 10.1007/s00376-015-5147-y.

In the original version of this article, the color bar in Fig. 3 is missing. The complete Fig. 3 is shown below.

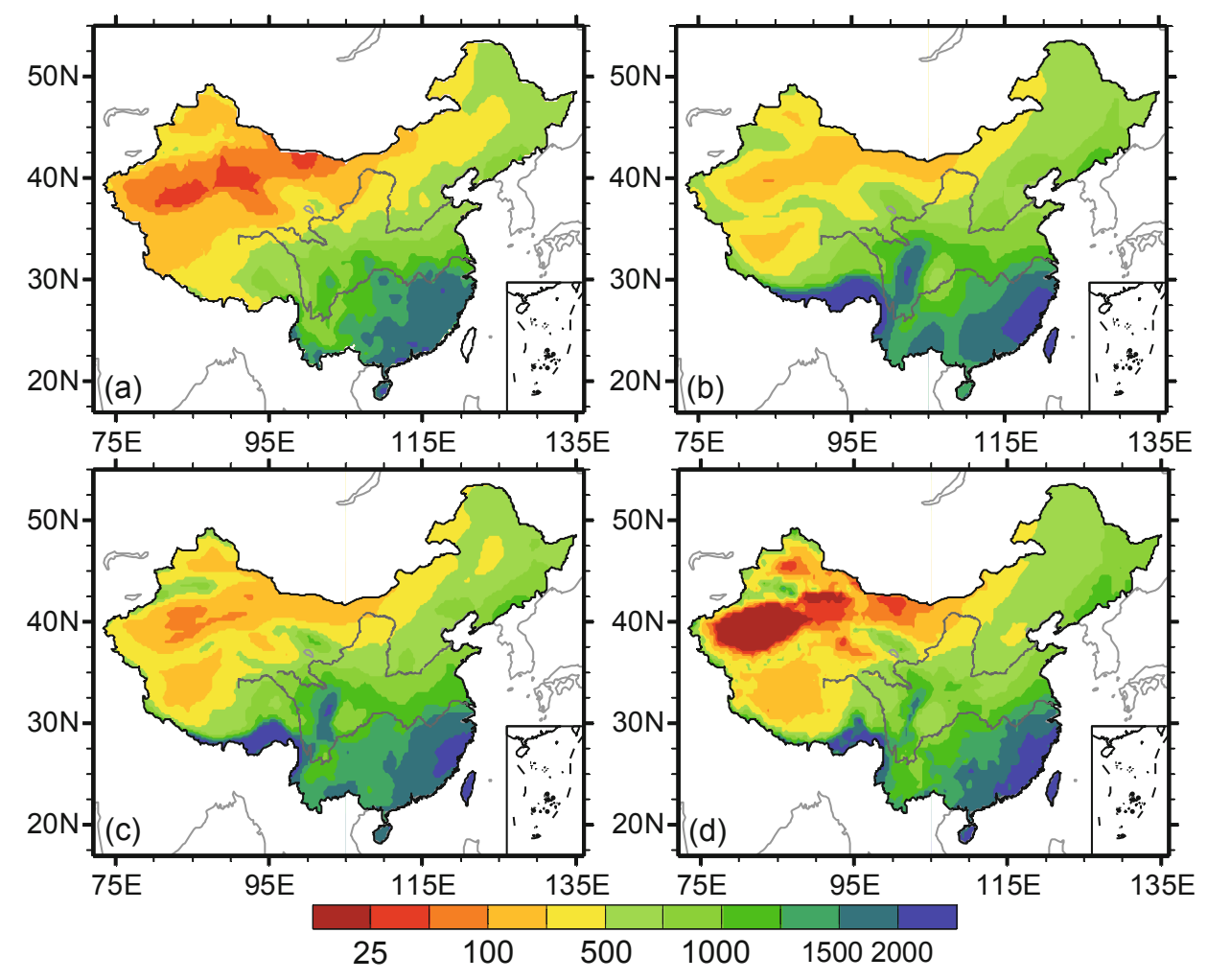

The online version of this original article can be found at http://dx.doi.org/10.1007/s00376-015-5147-y

(C) Institute of Atmospheric Physics/Chinese Academy of Sciences, and Science Press and Springer-Verlag Berlin Heidelberg 2016 